\title{
Myocardial Revascularisation - Current Perspectives and Controversies
}

\author{
Pankaj Kaul* \\ Consultant Cardiac Surgeon, Leeds General Infirmary, UK
}

Submission: February 07, 2018; Published: March 19, 2018

*Corresponding author: Pankaj Kaul, Consultant Cardiac Surgeon, Leeds General Infirmary, Great George Street, Leeds, LS1 3 EX, UK, Tel: 00441133925568; Email: pankajkaul784@btinternet.com

\section{Abstract}

The current management of coronary heart disease comprises medical, percutaneous and surgical therapies with significant advancement in each arm of treatment. We shall outline the contemporary history of the treatment of coronary heart disease, revascularisation guidelines and appropriateness criteria for different modalities of treatment, various randomised controlled trials (RCTs) and their meta-analyses comparing different methods of revascularisation for different categories of disease, the usefulness of multidisciplinary heart teams, the role of fractional flow reserve (FFR) estimation in guiding percutaneous interventions, the importance of surgical revascularisation without cardiopulmonary bypass, the parallel advances in percutaneous and surgical streams of treatment, risk prediction for the various modalities of treatment and informed consent. We shall conclude by summarising the current status of myocardial revascularisation based mainly on the plethora of international guidelines and multi-institutional protocols and, in some important aspects, on the work life experiences of a large number of talented and dedicated health professionals.

\section{Evolution of Coronary Revascularisation}

The Veteran Affairs Cooperative Study [1-4], the Coronary Artery Surgery Study [5-8], and the European Cardiac Surgery Study [9] were the three invaluable randomised controlled trials (RCTs) during 1970s and 80s that established unequivocally that coronary artery bypass grafting (CABG) provided superior relief of angina and improved survival compared to medical treatment, in patients with significant left main stem (LMS), triple vessel or double vessel coronary artery disease (CAD) including that involving proximal left anterior descending (LAD) artery, particularly with depressed left ventricular (LV) function or a positive treadmill test, although, historically, CABG revolutionised the treatment of coronary artery disease right since its inception [6].

In the landmark meta-analysis of seven randomised controlled trials (RCTs), including the above three, by CABG Trialists Collaboration group, reported in 1994 by Yusuf et al. [10] in Lancet, CABG provided an absolute risk reduction of $5 \%$ at 5 years and $4 \%$ at 10 years, and this extended to patients with good left ventricular function.

Percutaneous intervention (PCI), with balloon angioplasty (BA) alone, introduced first in 1977 [11], and later with Bare Metal Stents (BMSs), developed as the less invasive arm of revascularisation in 1980s. EAST, RITA-1, GABI and BARI RCTs, compared BA with CABG. EAST (Emory Angioplasty vs. Surgery Trial) was a single centre trial (1987-90), comparing 198 patients who underwent PCI with balloon angioplasty (BA) and 194 CABG patients, that showed similar survival at 8 year follow up, except in patients with proximal LAD involvement and in diabetics, where CABG was significantly better [12]. RITA1 (Randomised Intervention Treatment of Angina) was a multicentre trial based in the UK, comprising patients with less extensive disease (with $45 \%$ patients having single vessel disease), which showed no significant difference in death or MI between BA and CABG [13]. GABI (German Angioplasty Bypass Surgery Investigation) was an eight-centre trial based in Germany which randomised 359 patients out of 8981, excluded those with total occlusions and LMS stenoses, and, thereafter, not surprisingly, found comparable survival and symptom relief at 13 years [14]. BARI (Bypass Angioplasty Revascularisation Investigation), in 1988, had 1829 patients, and found comparable survival at 5 and 10 years with BA and $C A B G$, except in diabetics, in whom surgery was better [15].

ARTS (Arterial Revascularisation Therapies Study) [16], ERACI II (Coronary Angioplasty with Stenting vs. Coronary bypass surgery) [17], MASS II (Medicine, Angioplasty and Surgery Study) [18] and SOS (Stent or Surgery) [19] compared PCI with bare metal stents (BMSs) with CABG. The first three found no survival difference between PCI and CABG. SOS was the only trial which met to some extent the rigor of a scientific design. All 998pts that were screened were randomised, and the incidence of triple vessel disease was $63 \%$. Not surprisingly, SOS trial found significantly better survival with CABG compared to PCI with BMSs. 
A pooled analysis of the above four randomised controlled trials (RCTs) comparing CABG to PCI with BMSs showed significantly reduced major adverse cardiovascular and cerebral events (MACCE) with CABG (23\% vs. 39\%, P=0.001), driven mainly by significantly higher reintervention rates with PCIs (29\% vs. $7.9 \%)[20]$.

A meta-analysis of 23 RCTs from 1980 to mid 2000, comparing CABG to PCI with either/both BA and BMS, involving 5,019 patients with mainly single or double vessel disease, showed better angina relief with CABG ( $84 \%$ vs $79 \%, \mathrm{p} \leq 0.001)$, greater re-intervention rates with BA PCI (absolute risk increase of 33\% at 5 years, $\mathrm{p} \leq 0.001$ ) and slightly more frequent procedure-related stroke after CABG $(1.2 \%$ vs $0.6 \%, p \leq 0.002)$ and no difference in diabetics [21]. A Cochrane database review of RCTs of BMSs vs CABG revealed similar findings [22].

But that the results of the trials would show that there was a survival advantage only in diabetics or people over 65 was a self-fulfilling prophecy, because of the way the trials were designed [21,23]. Firstly, only 2-9\% of the screened population was randomised. In RITA, only 1011 out of the screened 17,237 patients were randomised, in CABRI (Coronary Angioplasty versus Bypass Revascularisation Investigation) only 1052 out of 42,000, and in AWESOME (Angina with Extremely Serious Operative Mortality Evaluation) only 454 out of 22662 [24].

Secondly, the patients randomised had very low incidence of triple vessel disease, precisely the group that has the maximum advantage from surgery. RITA had $12 \%$ patients with triple vessel disease, ARTS 32\% and GABI 18\%. In addition, only SOS trial randomised all screened patients (998) and had greater triple than double vessel disease (63\% and 57\%) and, as expected, showed significantly diminished survival at 6 years follow up in PCI patients.

Also, the majority of patients had normal left ventricular function. Only EAST, GABI and BARI had 19, 21 and 23 patients with $<51 \% \mathrm{LV}$ function. The rest eight randomised controlled trials had either not included any patients with reduced left ventricular function or did not mention it [25]. Despite such glaring inadequacies and limitations in these trials, the results of these trials, with carefully screened and selected groups, were then extrapolated to the entire gamut of three vessel and complex coronary artery disease, responsible directly for the explosive growth of PCI [26].

The results of three meta-analyses flew in the face of not only the surgeons' own real life experience but also the reports from nine large registries which showed a constant survival benefit and seven-fold reduction in re-intervention rates with CABG [2735]. Subsequently and more currently, however, 5 years follow-up data on SYNTAX (Synergy between PCI with Taxus and Cardiac Surgery) trial showed a clear survival benefit for patients with left main stem disease with high SYNTAX score $(>33)$ or with three vessel disease and intermediate or high SYNTAX score $(>22)$ with CABG [36].

\section{Decision Making by Teams and not Individuals}

Historically, patients were referred for cardiac surgery to cardiac surgeons by cardiologists based on their subjective opinion regarding what method of revascularisation was more beneficial and more effective for the patients. Quite often the decision was taken by the same group of cardiologists who would perform the percutaneous interventions themselves. There was an obvious scope for conflicts of interest to develop. Surgeons have complained for a long time the rampant overuse of PCI particularly in stable coronary artery disease. Organisation for Economic Corporation and Development (OECD) reported 218 coronary revascularisation procedures per 100,000 population across the countries, with PCI proportion of $72 \%$ in 2013 [37]. Germany has a PCI proportion of $84 \%$ with a revascularisation rate of 435 per 100,000 [38,39]. Increasingly multidisciplinary teams variously comprising clinical and interventional cardiologists and cardiac surgeons have undertaken decisions regarding the choice of revascularisation with reference to established European [40] and American guidelines [41-43] as well as individual institutional protocols in stable coronary artery disease and NSTEMIs. Apart from addressing the concerns regarding overuse of PCI in triple vessel disease and left main coronary disease due to anomalies and lack of transparency in the referral systems, there is evidence that clinical outcomes are better when multidisciplinary teams (MDTs) determine revascularisation strategy $[44,45]$. Interestingly there is also evidence that MDTs may not take decisions congruent with the latest guidelines outlining the importance of local and institutional protocols [46]. Different decisions regarding revascularisation may be taken at different points in time by the same team underscoring the fact that both PCI and CABG may be equally suitable in a number of different scenarios [47]. Participation of health professionals from specialities beyond the immediate cardiac surgery or cardiology, including anaesthetists, radiologists, transplantation experts and heart failure teams diversifies the treatment options available [48].

\section{Revascularisation Guidelines}

The previous practice guidelines from American College of Cardiology (ACC) and American Heart Association (AHA) were published before the results of trials comparing PCI with DESs to CABG were reported $[35,49,50]$. Recommendations for chronic stable angina remained unchanged in the 2007 update [49] and broadly were similar to unstable angina /non-ST elevation MI guidelines from 2007 [50]. The one year analysis of the SYNTAX trial showed significantly increased risk of re-intervention and MACCE and hence reduced survival with PCI as compared to CABG in patients with previously untreated three vessel or left main coronary artery disease. This was particularly striking in patients with SYNTAX scores above 33 [51].

In an effort to provide comprehensive guidance beyond the evidence based guidelines which usually were either unavailable or only partially available for a wide spectrum 
of clinical scenarios, an expert panel of 17 members, which included 4 cardiac surgeons and 4 interventional cardiologists, was constituted while writing groups provided various clinical vignettes. The vignettes were scored for appropriateness of revascularisation (PCI or CABG) on a scale of 1 to 9. In general, PCI was rated as appropriate for acute myocardial injury and for most scenarios where there was significant coronary disease with ischaemic symptoms despite adequate medical therapy. The risk of appropriateness for PCI increased as the extent of myocardium at risk increased till the threshold of triple vessel coronary artery disease was reached. For patients with triple vessel disease, PCI was rated uncertain regardless of the presence of diabetes or left ventricular dysfunction. PCI for left main stem disease was rated inappropriate. CABG was rated appropriate for triple vessel and left main coronary artery disease in all settings. The findings of this document were jointly published in the Journal of American College of Cardiology and Circulation [52]. Lesion complexity did not figure in the scenarios and vignettes, which could severely affect the results of PCI. CABG, on the other hand, was seen to be unaffected by SYNTAX score, which, in turn, is a surrogate for lesion complexity.

5 year Syntax trial, however, subsequently, has clearly shown that in patients with triple vessel coronary artery disease treated with CABG or PCI using first-generation Paclitaxel-eluting stents, CABG should remain the standard of care as it resulted in significantly lower rates of death, MI and repeat revascularisation, while stroke rates were similar. For patients with low SYNTAX scores, $\mathrm{PCI}$ is an acceptable revascularisation strategy, although at the cost of a significantly higher rates of repeat revascularisation [36].

The various recent guidelines on myocardial revascularisation by different American Societies include the ACCF/AHA Guidelines for CABG Surgery (2011), the ACCF/AHA/ACP/AATS/PCNA/ SCAI/STS guideline for the diagnosis and management of patients with stable ischaemic heart disease (2012), the ACC/AHA/AATS/ PCNA/SCAI/STS focussed update (2014) and STS Clinical Practice Guidelines on Arterial Conduits (2015) [41-43,53,54]. Only the Focussed Update and STS Guidelines published respectively in 2014 and 2015 have been published after the 5 year results of SYNTAX trial became available in 2013. American trials expectedly, therefore, are less cognizant of SYNTAX results. Both 2011 and 2012 ACCF/AHA guidelines recommended CABG for left main coronary artery disease, triple vessel coronary artery disease with or without proximal LAD disease, two vessel disease with proximal LAD disease, two vessel disease without proximal LAD disease with extensive ischaemia and single vessel proximal LAD disease. Only when the risk of adverse outcomes after surgery was high and procedural complications after PCI low, as in ostial or mid-shaft left main stem stenosis or less often with distal bifurcation lesion with SYNTAX $<33$, was PCI recommended with class II a or II b and LOE B recommendation.

The EACTS/ESC joint Guidelines on Myocardial Revascularisation were published in 2014. The European guidelines have a class 1 recommendation for surgery for proximal LAD stenosis, left main stenosis and any triple vessel coronary disease, with level A or B evidence. PCI is suggested as an alternative for patients with one or two-vessel disease with proximal LAD stenosis, left main stenosis with a low or intermediate SYNTAX score and three-vessel disease with a low SYNTAX score. One or two vessel-disease without proximal LAD stenosis should have PCI as the primary treatment [40].

Both guidelines emphasise Heart Team approach and multidisciplinary decision-making. American Heart Team comprises of a surgeon and an interventional cardiologist whilst European multi-disciplinary team is in a more conference style, involving at least a surgeon, an interventional and non-interventional cardiologist and occasionally radiologists, anaesthetists, etc.

\section{Timing of Revascularisation}

All patients with ST elevation myocardial infarction (STEMI) should have primary emergency PCI to the coronary artery most likely to have caused STEMI [54]. All patients with mechanical complications of STEMI including post-infarction ventricular septal defect (VSD), acute mitral incompetence due to papillary muscle rupture or left or right ventricular rupture with tamponade are at considerable risk of dying without an operation and should have high risk immediate surgery unless outcomes are deemed to be hopeless. A small group of patients with large infarcts and small VSDs may benefit from a more watchful and expectant approach. Patients with STEMI and critical left main stem stenosis not amenable to PCI, or those with continuing ischaemia of large myocardial territories not amenable to PCI usually require urgent CABG. CABG in patients who are otherwise suitable for primary PCI has worse outcomes.

Patients with non-ST elevation myocardial infarction (NSTEMI) or acute coronary syndrome (ACS) should have urgent revascularisation within 24 to 72 hours according to European guidelines but more realistically within a week. Evidence of ongoing ischaemia like chest pain, dynamic ECG changes and rising troponin levels should prompt immediate intervention [40]. The choice of revascularisation method follows the same considerations as in stable coronary artery disease.

Patients with stable coronary artery disease without severe symptoms should have a revascularisation procedure within 6 weeks. Revascularisation should be performed more expeditiously, within 2 weeks or so, or even earlier, if symptoms are severe, if coronary anatomy is dangerously compromised or if ventricular function is significantly depressed.

\section{Stents}

Elastic recoil, vessel contracture and neointimal hyperplasia are in varying measures responsible for restenosis after balloon angioplasty [55-57]. Bare Metal Stents (BMSs) prevent recoil and contracture but exacerbate hyperplasia [58-60], while Drug Eluting Stents (DESs), which comprise a bare metal backbone (platform), a durable polymer and anti-proliferative agents such 
as Everolimus, Biolimus or Sirolimus, Paclitaxel, Zotarolimus, etc counter all three [60]. A meta-analysis of various trials that involved 5216 patients found no significant difference in death or MI at 4 years between DES (Sirolimus or Paclitaxel eluting) or BMS, but re-intervention rates were greatly reduced by both DESs (Sirolimus $7.8 \%$ vs $23.6 \%$; Paclitaxel $10.1 \%$ vs $20 \%$ ) [61]. A meta-analysis of 38 RTs and 18,203 patients with 4 years follow up reported similar findings [62]. Initial randomised controlled trial that led to FDA approval were limited to solitary, previously untreated, less than $3 \mathrm{~cm}$ long lesions in $2.5-3.75 \mathrm{~cm}$ arteries. But unrestricted off-label use showed similar trend of less reinterventions even in small vessels, diffuse disease, diabetes, long lesions, occlusions, SVGs and primary PCI, mainly from registry data [63-75].

Stent thrombosis is a dreaded complication of PCI with death rates of $31 \%$ [76]. Meta-analysis of 14 randomised trials suggested DES led to 4 to 5 -fold increase in very late (greater than 1 year) thrombosis, but the meta-analysis excluded events after repeat revascularisation, known to be required more often in BMSs, and so the analysis perhaps ended up slightly biased against DESs [77]. A further meta-analysis showed similar rates of definite or probable thrombosis at 4 years after PCI with BMSs or DESs (Sirolimus 1.5\% vs 1.7\%; Paclitaxel 1.8\% vs. 1.4\%) [76]. Two other meta-analyses of RCTs comprising 23,284 patients found similar rates of thrombosis within 4 years of PCI, but most thromboses with BMSs occurred within 1 year and those with DESs during 2nd, 3rd and 4th years [61,62]. Hypersensitivity reactions to the durable polymer component of the first- generation DES produces chronic inflammation which complicates endothelial healing and promotes stent thrombosis. Stent thrombosis (ST) is classified as early ( $>30$ days), late (31 days to 1 year), and very late ( $>1$ year).

The second-generation DES used less bulky struts, biocompatible but permanent polymer to reduce inflammation and hypersensitivity reactions and newer anti-proliferative agents. The third-generation stent technology includes the use of bio-absorbable stents, which might in turn be bio-absorbable polymer stents where the polymer degrades or stents with bioabsorbable metallic backbone [54].

A pooled analysis of three RCTs [78-80] by Stefanini et al. [81] compared BP-DES (biodegradable polymer), including BP-DES and BP-SES, with durable DES including DP-PES (durable polymer) and DP-EES with respect to mortality, myocardial infarction (MI), late stent thrombosis (ST) and target lesion revascularisation (TLR). It was found that compared to DP-DES, BP-DES was associated with a statistically significant lower rate of MI (HR 0.59) and ST (HR 0.22 ) including in diabetics characterised by lower ST (HR 0.45) [82].

The bio-absorbable stents need a shorter mandatory period of the use of dual anti-platelet medication after stent deployment and hence may be useful in patients who need early non-cardiac surgery after PCI.

\section{FFR and iFR}

Fractional flow reserve (FFR) utilises a specialised guidewire to measure blood pressure within a coronary artery after inducing maximum hyperaemia in the vessel with a pharmacological agent like Adenosine intravenously or as a high-dose intracoronary bolus, mainly to aim at a near-linear correlation between coronary arterial pressure and flow [83]. FFR is the ratio of the mean pressure distal to stenotic artery and the mean aortic pressure and its estimation enables assessment of the functional significance of a coronary stenosis incorporating variables like arterial stenosis severity, myocardial territory subtended by the relevant vessel, myocardial viability and collateral perfusion. There is a clear correlation between FFR with non-invasive functional testing as confirmed by many published reports [84]. Multiple randomised controlled trials confirmed improvement in the sensitivity when the cut-off of trans-lesional functional assessment with FFR was increased to 0.80 from the initial 0.75 , indicating that coronary pressure is reduced by $20 \%$ [85]. FFR offers a scientific approach to physiologic lesion assessment for coronary revascularisation in intermediate lesions and severe lesions with 70-90\% severity with respect to stable angina, non-culprit lesions in unstable angina and acute coronary syndromes, and should be used to guide interventions. FFR remains underutilised currently with only $6.1 \%$ intermediate level stenoses being guided by FFR, despite long-term data showing its benefits in determining whether patients would benefit from revascularisation or medical therapy [86].

Instant wave-free ratio (iFR) offers a drug-free and more physiological measurement of the severity of stenosis, given the documented limitations of hyperaemia and adenosine use, without sacrificing accuracy [87,88]. FFR and iFR show no difference in predicting myocardial ischaemia when compared to $13 \mathrm{~N}$-ammonia positron emission tomography [89]. Two RCTs, in addition, confirmed the non-inferiority of of iFR-guided revascularisation as compared to one guided by FFR $[90,91]$.

DEFER, a prospective RCT in 2001 comprising 325 patients at 14 medical centres, found that patients with single vessel disease with angiographic stenosis greater than $50 \%$ but FFR greater than 0.75 had similar composite MI or death rates irrespective of whether PCI was performed or not thus showing no benefit in stenting a non-ischaemic lesion [92]. In the FAME study in 2009 comprising 1005 patients at 20 medical centres, similarly, patients with multi-vessel disease treated with PCI were randomised to receive either PCI to all angiographically significant lesions or to only angiographically significant lesions with FFR less than 0.8. At 1 year, re-intervention, MI and death rates were less in FFR guided arm of the study (13.2\% vs $18.3 \%$ ), and these patients received fewer stents. Thus, routine measurement of FFR in patients with multi-vessel CAD who underwent PCI with DESs significantly reduced MACE at 1 year [85]. The 2012 FAME 2 study, comprising 888 patients at 28 medical centres with stable CAD and haemodynamically significant stenosis found FFR-guided (cut-off 
0.8) PCI with DES + optimal medical therapy (OMT) vs OMT alone decreased the rate of urgent revascularisation. OMT alone resulted in excellent outcomes, regardless of the angiographic appearance of the stenoses [93,94]. Muller et al. [95] in 2011 studied 730 patients at one Belgian centre and found medical treatment was associated with favourable long-term clinical outcomes in angiographically equivocal lesions which were non-ischaemic by FFR (cutoff 0.8). The 2013 retrospective Mayo Clinic registry of 7358 patients undergoing PCI, except those with STEMI or cardiogenic shock, showed FFR-guided management resulted in a favourable long-term outcome with decreased MACE [96]. Van Belle et al. [97] in a 2014 prospective observational study of 1075 patients at 20 French centres with angiographically ambiguous lesions concluded that FFR during diagnostic angiography is safe and associated with reclassification of the revascularisation decision in half of the patients [98]. RIPCORD, the prospective observational study of 200 patients with stable angina at 10 centres in the UK found FFR influences identification of arteries that have significant stenosis and thus management of coronary artery disease (CAD). DANAMI-3-PRIMULTI prospective RCT in 2015 of 627 patients with STEMI and multi-vessel CAD who had undergone primary PCI of an infarct-related artery, at two centres in Europe, concluded that FFR-guided complete revascularisation during the index admission resulted in lower future events, mainly due to reduced need for repeat revascularisation [99]. Compare-Acute trial of 885 patients at 24 centres in Europe and Asia in 2017 concluded that there was lower MACE mainly due to lower revascularisation when revascularisation of non-infarct, non-culprit arteries in the acute setting was guided by FFR in patients with STEMI and multi-vessel disease who had undergone primary PCI of an infarct-related artery [100]. IRIS-FFR prospective registry of 5846 patients with at least one coronary lesion demonstrated that the risk of MACE was significantly lower when percutaneous intervention was undertaken in arteries with FFR $<0.75$ as compared to the deferred lesions and that the risk was not significantly different between revascularisation and deferred therapy when FFR was $>0.76$ [101].

Clearly, there is strong clinical trial evidence to suggest that FFR $<0.8$ is abnormal and suggestive of downstream inducible ischaemia. A suggested algorithmic approach recommends, with respect to stable angina, FFR estimation for all intermediate lesions of $50-70 \%$ stenosis and severe lesions of $70-90 \%$ stenosis (a recent consensus statement suggested that $20 \%$ of these 70 $90 \%$ stenoses are not haemodynamically significant [102] and intervention if FFR is less than 0.8 and medical treatment if FFR is greater than 0.8 . FFR is not recommended in lesions with $>90 \%$ stenosis. In unstable angina/ACS, whilst FFR is not recommended in the culprit lesion, in the non-culprit lesion, an FFR $<0.8$ warrants intervention [103].

\section{Surgical Revascularisation}

CABG is the most studied and analysed operation in the world and although it is performed in older patients with greater comorbidities and more complex disease than before, the perioperative mortality rates have continued to decline and are currently reported to be between 1 to $2 \%$ [104-107]. These improvements are a direct result of improvements in anaesthesia, cardiopulmonary bypass, myocardial preservation, conduit choice and treatment, postoperative care and secondary prevention [104]. Sixth National Adult Cardiac Surgical Database Report 2008 for the SCTS (Society of Cardiothoracic Surgery in Great Britain and Ireland) reported $1.79 \%$ overall mortality for all primary CABG and $0.61 \%$ for patients under 56 years [108]. In the last two decades, there has been a steady use of off-pump coronary artery bypass grafting (OPCAB) and the use of multiple arterial bypass conduits.

\section{OPCAB}

During conventional CABG with cardiopulmonary bypass, exposure of blood to artificial tubing, filters and reservoirs can, in a very small number of patients, lead to a systemic inflammatory response syndrome, which might, in turn, lead to organ dysfunction [109]. In an attempt to avoid this pro-inflammatory syndrome, and, more importantly, to avoid the transient global ischaemia associated with aortic cross clamping during conventional bypass, OPCAB is performed in a beating heart through traditional median sternotomy without CPB. Despite evidence of a reduction in the release of inflammatory markers $[110,111]$ and markers of myocardial injury [112], rates of death, MI and stroke appear to be the same in various RCTs $[106,113]$. A meta-analysis of 37 RCTs showed no difference in 30 days mortality, MI, stroke, wound infection and re-Intervention rates, although there was reduction in $\mathrm{AF}$, inotropic support, respiratory infection, ventilation-time and ICU and hospital stays [106]. However, another meta-analysis that included registry data showed reductions in perioperative deaths, MI and stroke [114]. A scientific statement by AHA in 2005 conceded OPCAB led to less blood loss, less perioperative enzyme release, less transient neurological dysfunction (TND) and less renal insufficiency than traditional CABG [115], but the 2009 meta-analysis of 10 RCTs found no significant difference in death, stroke, MI or repeat revascularisation [115].

ROOBY (Randomised on-pump versus off-pump coronary artery bypass surgery) Trial looked at 2203 patients at 18 centres who were randomised to either on-pump or off-pump CABG [116]. There were no significant differences in 30 day outcome of death or major morbidity and no major differences in neuropsychological outcomes or use of major resources but significantly worse graft patency with off-pump CABG (82.6\% vs. $87.8 \%, \mathrm{P} \leq 0.01$ ) and significantly worse 1 year composite outcome with off-pump CABG (9.9\% vs. $7.4 \%, \mathrm{P}=0.04)$ and significantly worse complete revascularisation with off-pump CABG $17.8 \%$ had fewer grafts completed than intended in off-pump group as against $11.1 \%, \mathrm{P} \leq 0.001)$. The characterising features of the trial included the fact that $77.2 \%$ of the originally enrolled patients (7460 out of 9663) were excluded due to either small diffuse vessel disease or failure or refusal to enrol. Secondly, most patients were 
white males with good ventricular function and triple coronary artery disease. 53 surgeons with average off-pump experience of 120 cases took part in the trial and $16 \%$ patients were excluded from the trial because of conversion from off-pump to on-pump surgery (12.4\%) or conversion from on-pump to off-pump surgery (3.6\%). The main criticism of the trial included the fact that $99 \%$ were male patients, average age was only 63 years, most patients had good left ventricular function and the operations were not always done by operators who could be considered experts in offpump surgery.

German off-pump coronary artery bypass in elderly study (GOPCABE) comprising 2539 patients (69\% of eligible), completed in July 2011, with primary end points of all come mortality and MACCE at one and twelve months found no difference in clinical outcomes at 30 days and at 12 months [117].

Danish off-pump on-pump randomisation Study (DOORS) of 900 patients demonstrated that both conventional CABG and OPCAB are safe procedures that improved the quality of life in elderly patients with no major differences in intermediate-term outcomes. However, the non-inferiority of OPCAB with the prespecified margin could not be proved [118].

The 2011 ACCF/AHA Guidelines for CABG Surgery [41], following on from the non-specific equipoise of the earlier trials and statements [110-115] and the more definite negative findings of the more controversial ROOBY trial published in 2009 [116], made no formal recommendations apart from conceding that most surgeons considered both approaches to be reasonable in most patients and that patients with unstable haemodynamics could be more easily managed with conventional CABG and those with aortic atherosclerotic disease with off-pump CABG. European Guidelines in 2014 [40], however, were more definitive in recommending off-pump CABG in patients with atheromatous aortic disease and that sub-set of patients at higher risk of sustaining neurological injury after CABG.

The CABG Off or On Pump Revascularisation study (CORONARY), published in 2016, which randomised 4752 patients to compare the results of on-pump with off-pump CABG found no significant differences between the two groups in the rate of death, nonfatal stroke, nonfatal myocardial infarction, or the nonfatal new renal failure requiring dialysis or in the rate of subsequent revascularisation procedures or quality of life or neurocognitive function [119].

Despite the mixed results enumerated above, it is likely OPCAB provides some degree of protection for patients with atheromatous or calcified aortas. Conventional CABGs are mostly preferred in all other patients, in patients requiring emergency or urgent surgery and in patients with severe coronary disease requiring better exposure [104,105]. Incidence of off-pump surgery in different countries is highly variable guided partly by economics, long-term follow up data and training. $17 \%$ of all CABG in the UK are done off-pump [108]. This ratio is a lot higher in other countries-in USA about 35-40\% and in India around 75$80 \%$.

In summary, the available incidence seems to suggest that OPCABG when performed by appropriately trained surgeons can be performed as safely as ONCABG. However, there is accumulating evidence that off pump grafts may be inferior both in number and quality. Zhang et al. [120] confirmed reduced graft patency in a meta-analysis of RCTs. Takagi et al. [121] reported a meta-analysis of RCTs and observational studies in over 100,000 patients with a worse five year survival amongst off-pump patients. If this is confirmed by further studies, off-pump CABG might end up being reserved for patients with atheromatous aorta only.

\section{Multiple Arterial Bypass Grafts}

The superiority of left internal mammary artery over saphenous vein graft as a conduit to LAD has been presumed since 1980s, when 10 years patency rates of LIMA were shown to be 80 to $95 \%$ [122-127]. Attempts to replicate these patency rates by using other arterial conduits to arteries other than LAD have not been equally successful [128]. This arguably has more to do with the recipient arteries that subserve a particular myocardial territory and the quantum of run-off in the recipient myocardial territory than the nature of conduit itself and is governed by Poiseuille's Law:

$$
\begin{gathered}
F=\frac{P 1-P 2}{R} \\
R=\frac{8 v L}{3.14 r^{4}} \\
F=\frac{3.14 r^{4}(P 1-P 2)}{8 v L}
\end{gathered}
$$

where $\mathrm{F}$ is Flow rate through a hollow tube, PI-P2 the pressure difference across the hollow tube, $\mathrm{R}$ the resistance to flow, $\mathrm{v}$ : viscosity, L: Length of tube and 3.14 the value of the constant pi.

Poiseuille's law states that the fluid flow through a hollow tube is directly proportional to the pressure difference and inversely proportional to the resistance. The resistance in turn is directly proportional to the length of the tube and viscosity of the fluid and inversely proportional to the 4 th power of the radius. In other words, if the length of the graft, or viscosity of blood is doubled, the flow through the graft will be halved. Again, if the pressure gradient is doubled, the flow through the graft will be doubled and more crucially if the radius of the graft is doubled, the flow through the graft increases 16 times, and if the radius is halved, the flow drops to 1/16th of the original flow. Because left anterior descending artery (LAD) quite often is diseased proximally before major branches are given off from it, the total run off beyond the proximal disease is huge, significantly larger than in a marginal circumflex (Cx) branch or distal right coronary artery or PDA graft. Therefore, any graft will stay patent longer on an LAD than on any other vessel because of the greater possibility of a better run-off in the recipient myocardium, independent of the conduit used. This 
explains, more than the vessel-wall differences between veins and arteries or between arteries from different anatomical sites used as conduits, why arterial grafts on other coronary arteries are not equally successful. Quite often, in the studies in 1980s with the possible exception of that of Lytle, patency of left internal mammary artery (LIMA) to LAD was compared to either all vein graft patencies or to patencies of saphenous vein grafts (SVGs) to arteries other than LAD. Not infrequently, LIMA is smaller in diameter than the recipient LAD, and, therefore, the flow tends to be limited at the graft-level rather than at the recipient-vessel level, as is often the case with other grafts. It stands to reason therefore that anastomosing a particularly small LIMA to exceptionally large LAD might produce a mismatch resulting in relative ischaemia of the recipient myocardial territory and should be avoided.

Using both internal mammary arteries (BIMAs) in multivessel disease has been evaluated in multiple observational studies $[129,130]$ and a few meta-analyses suggest dual IMAs lead to better survival than single IMA and SVG [131-133]. However, not all studies have found these benefits [134]. Five year data from Randomised Trial of Bilateral versus Single Internal-ThoracicArtery Grafts (ART), published in 2016, showed no significant difference in clinical outcomes between the two groups although sternal wound complications were higher in the bilateral-graft group [135]. RIMA harvest adds another half hour to the operation and the previous claims of increased risk of mediastinal infections increasing by 2.5 to 5 fold [136], although not fully proven by 5 year data from the ART trial, have not been silenced either, despite more frequent skeletonised technique of IMA harvest.

Radial artery (RA) is a good conduit, and although it is slightly more prone to spasm during harvest, it should generally be anastomosed to a relatively severely diseased artery $[104,105]$. One RCT and several observational studies provide no conclusive proof that they are, in short term or intermediate term better than vein grafts [137]. Studies with follow-up beyond 10 years might clarify the situation better regarding RAs. A 12-year observational study shows 12- year survival was better with 2 or more arterial grafts than with 1 arterial and the rest vein grafts [138]. The 2011ACCF/AHA guidelines [41], the 2014 ESC/EACTSGuidelines [42], and the STS Practice Guidelines [53] concede that RA patency may be higher than the vein grafts but only if it is grafted to a vessel with greater than $70 \%$ stenosis on the left side and $90 \%$ on the right side [41]. RAs are also shown to fail not just by occlusion but also by being non-functional whilst staying patent [139]. Pharmacological dilatation seems to be required more frequently both intraoperatively and perioperatively with radial arteries.

Saphenous vein grafts remain the work-horse grafts of coronary artery surgery. Except when saphenous vein is involved with varicosity or thrombosis, it has the advantage of revascularising entire heart due to its length, something that multiarterial grafting often fails to do completely. By virtue of its better diameter compared to arterial grafts, vein grafts provide immediate high flows not limited at the graft level but only possibly limited at the recipient myocardial level, which remains the yardstick by which all coronary grafts need to be measured. A basic principle of coronary artery bypass grafting remains the fact that all bypass grafts should carry more blood in them than can run off in the recipient myocardial coronary system (luxurious blood flow) so that blood flow in the recipient myocardial coronary system is never ever limited at the graft level. We have seen from Poiseuille's Law previously that reductions in radius of the graft by half will reduce blood flow 16 times. This applies to both venous and arterial grafts, but because of their anatomic properties, it has special application to small diameter internal mammary arteries and small diameter radial arteries, which might be occasionally be flow-limited at the graft level owing to their size rather than at the recipient myocardial level, although blood flow in small IMAs and radial arteries is shown to increase over a period of time.

There are a number of observational studies of total arterial OPCAB with excellent short term and intermediate term results, but their superiority has not been proven by randomized studies [140-145]. There is a relative paucity of data on total arterial revascularisation with respect to incremental benefit as compared to LIMA/SVG, LIMA/RA/SVG and BIMA/SVG, with some reports being encouraging but none persuasive enough to warrant a change in practice informed by hard data [146-153].

\section{PCI with DESs vs. CABG in Multi-Vessel Disease}

Comparative data of outcomes between CABG and PCI with Drug Eluting Stents (DESs) comprises mainly several observational studies which generally show similar rates of death, MI and stroke, but more frequent repeat revascularisation after PCI [154-162]. New York registry data [155] and that by Javaid [156], however, suggest better survival with CABG. Hannan [154] found survival benefit with CABG when EF was low and Park [158] found no benefit.

SYNTAX trial [163] was the first large randomised prospective controlled trial of PCI with DESs vs CABG in severe coronary artery diseae (CAD). This screened 4337 patients with triple vessel or left main stem disease, out of which 3075 were eligible and 1262 ineligible. Out of these, 1800 were suitable for PCI or CABG (1077 only for CABG and 198 only for PCI and these were entered into nested registries). The study failed to meet its primary end point. At 12 months, the primary outcome of MACCE occurred more frequently after PCI than after CABG $(17.8 \%$ vs. $12.4 \%$ : $\mathrm{P} \leq 0.002)$, driven mainly by higher rates of revascularisation after PCI $(13.5 \%$ vs. $5.9 \%$ ). The rates of death and MI were similar, but stroke occurred more often after CABG, with half the strokes occurring 3 months after surgery ( $2.2 \%$ vs. $0.6 \%$; $\mathrm{P}=0.003)$. The rates of symptomatic graft occlusion after CABG and stent thrombosis after PCI were both $3 \%$.

Subsequently, 5 year results of SYNTAX trial, as reported by Mohr et al. [164], looked at these 1800 patients randomly assigned to $\mathrm{CABG}$ or PCI. Both $\mathrm{MI}$ and repeat revascularisation rates were 
significantly higher in the PCI group (9.7\% vs $3.8 \%$ and $25.9 \%$ vs $13.9 \%$ respectively). This drove the Kaplan-Meier estimates of MACCE to $37.3 \%$ in PCI and $26.9 \%$ in CABG $(\mathrm{p}<0.0001)$ at 5 years. Whilst there was no significant difference in MACCE between two groups when SYNTAX scores were less than 22, in patients with intermediate (23-32) and high (>33) SYNTAX scores, MACCE was significantly increased with PCI as compared to CABG $(36 \%$ vs $25.8 \%$ with intermediate SYNTAX scores and $44 \%$ vs $26.8 \%$ with high SYNTAX scores). There was no significant difference in the all-cause death and stroke between PCI and CABG (13.9\% vs $11.4 \%$ and $2.4 \%$ vs $3.7 \%$ respectively) [36].

5 year results of SYNTAX trial thus clearly established that CABG should remain the standard of care for patients with CAD with high or intermediate scores. For patients with single (LAD), double or multiple vessel disease with low SYNTAX scores or left main coronary disease with low or intermediate SYNTAX scores, PCI is an acceptable alternative. It is, therefore, useful to discuss all patients with multi-vessel coronary disease, particularly those with low and intermediate SYNTAX scores in a multi-disciplinary meeting or by a Heart Team comprising at least a surgeon and both interventional and non-interventional cardiologists to reach consensus [154].

\section{PCI with DESs vs CABG in LMS}

A review of 10 year results of RCTs by CABG Trialists collaboration in 1994 had already shown clear survival advantage of CABG over medical therapy in patients with $\geq 50 \%$ LMS stenosis [10]. In Insights from the SYNTAX run-in phase, published in Eur J Cardiothor Surg, Kappatein et al. [165] found 215 patients in North America and 26\% patients in Europe with LMS were treated with PCI. Taggart \& Mack [166] summarised results of 7 groups comprising PCI with DESs in 599 patients: In hospital and 11 month mortality was $2.4 \%$ and $11 \%$ respectively, immediate and repeat revascularisation $2 \%$ and $13 \%$ and peri-procedural MI $6 \%$. Others have reported better results [166,167] particularly when distal bifurcations or trifurcations are not involved [168,169]. To date there has been 1 RCT comparing PCI with DESs in LMS disease [170]. In one year sub-group analysis of LMS patients in SYNTAX trial, more frequent repeat revascularisations were required after DESs ( $2 \%$ vs $7 \%, \mathrm{P}=0.02)$, but more frequent strokes were seen after CABG (0.3\% vs. $2.7 \%, \mathrm{P}=0.01$ ) [52]. This increased stroke risk was not seen, interestingly, at five year follow-up of the SYNTAX trial [36]. Even though CABG is the standard treatment for LMS disease, PCI in non-distal, non-bifurcating or non-trifurcating lesions may achieve at least comparable results at 1 year. 5 year results of SYNTAX trial, as reported by Mohr, suggested that for patients with left main stem stenosis, CABG remains the standard of care but for those with low or intermediate SYNTAX scores, PCI is an acceptable alternative [36].

\section{Predicting Procedural Risk and Risk from Comorbidities}

Risk models are widely employed for prediction of outcomes after cardiac surgery in general and coronary artery surgery in particular. In addition to their use in assessing the relative impact of specific risk factors on mortality, risk models are useful for patient counselling, selection of treatment streams, quality improvement programmes, audit, and comparison of results across institutions and surgeons. The first risk model was the Parsonnet score which was based on retrospective analysis of data obtained during 1980s. Risk modelling in cardiac surgery and coronary revascularisation in particular has since been driven by advances in techniques and interventional technology. At least 19 risk-stratification models are known that predict risk in cardiac surgery. They vary in the region and the number of centres they are used and hence the number of patients they cover, the number of risk variables, year of publication and the years of data collection. These include Amphiascore, Cabdeal, Cleveland Clinic, Additive EuroSCORE, logistic EuroSCORE, French score, Magovern, NYS, NNE, Ontario, Parsonnet, modified Parsonnet, Pons, STS risk calculator, Toronto, Toronto modified, Tremblay, Tuman and UK national score. At one end of the spectrum, Cabdeal model from Finland used data collected in 1990-91, published its results in 1996, was used in 386 patients, in only one centre and had 7 variables. STS risk calculator, on the other hand, was based in the USA, gathered data from 2002-2006, published it in 2007 and is used in 819 centres and covers 774881 patients and has 49 variables [171]. Euroscore for CABG to predict mortality identified the following factors, with different weightage: higher age, female sex, chronic pulmonary disease, extra cardiac arteriopathy, neurological dysfunction, serum creatinine $\geq 200$ micromol/l, previous cardiac surgery, active endocarditis, critical preoperative state, unstable angina with requirement for intravenous nitrates, reduced left ventricular function, recent MI, PA systolic pressures $\geq 60 \mathrm{mms} \mathrm{Hg}$, emergency surgery, major cardiac procedure other than or in addition to CABG, thoracic aorta surgery and surgery for post infarct VSD [172]. The weightage of the variables differs in the simple additive EuroSCORE and the later logistic version. The weights or scores are added to give an approximate percentpredicted mortality. The simple additive EuroSCORE is wellestablished and well-validated model of risk prediction and has served as a valuable tool of quality control across patient groups. However, in high risk patients, the simple additive EuroSCORE underestimates risk, particularly when certain combinations of risk factors coexist. Although logistic EuroSCORE produces more accurate risk prediction, particularly for the higher risk patients, the weightage to various variables and the calculation itself is complex [173].

The various risk scores currently in use for predicting risk following coronary artery surgery, including EuroSCORE 1 and 2, STS score and ACEF score, achieve a degree of reliability in predicting short-term mortality but there are very few predictive scoring systems for long-term and even intermediate-term outcomes. A predictive tool that could identify the superior revascularisation method, the SYNTAX SCORE was set up as part of SYNTAX STUDY [174]. This characterises a patient's coronary artery disease (CAD) with respect to the number of lesions, their location and functional impact and complexity. In patients with 
a SYNTAX score of 33 or greater, MACCE (major cardiac and cerebrovascular events) was twice as high after PCI (23.4\%) vs CABG $(10.9 \%)$ at 1 year. In the analysis of SYNTAX trial at 5 years, whilst there was no significant difference in MACCE between two groups when SYNTAX scores were less than 22, in patients with intermediate (23-32) and high (>33) SYNTAX scores, MACCE was significantly increased with PCI as compared to CABG $36 \%$ vs $25.8 \%$ with intermediate SYNTAX scores and $44 \%$ vs $26.8 \%$ with high SYNTAX scores). Although there was no significant difference in the all-cause death and stroke between PCI and CABG at 5 years (13.9\% vs $11.4 \%$ and $2.4 \%$ vs $3.7 \%$ respectively) [40], SYNTAX score has increasingly been identified to have a longer-term riskpredictive value.

All afore-mentioned risk scores have not been applied concurrently, and they do not always help estimate the risk benefit ratio. Because high procedural risk will be present in patients who will derive maximum benefit, like LV dysfunction, they do not determine the relative merits of one approach over the other because many risk factors are shared. However, SYNTAX score $(\geq 33$ ) identifies patients whose MACCE will be significantly higher after PCI than CABG. Patients with one or the other comorbidity tend to do better with one procedure or the other [175-188].

The risk profile with PCI has different risk spectrum although there are overlapping variables with CABG. The following eight variables were significantly correlated with procedural complications during PCI: cardiogenic shock, congestive heart failure class 3 or higher, LMS disease, multi-vessel disease, urgent or emergent procedure, thrombus, severe renal disease, older age [189].

There is increasing evidence that previous PCI in patients with triple vessel coronary disease is an additional risk factor for reduced survival following CABG, particularly in diabetics [190]. This is on account of a number of reasons:

a) Prior PCI is a proxy-marker for a more aggressive form of coronary disease.

b) Stenting prevents protective collateralisation and results in a more acute presentation.

c) Stenting produces peri-procedural myocardial injury, local vascular inflammation as well as formation of platelet microaggregates and microvascular plugging from plaque debris and embolisation in the distal vessel [191].

d) Graft anastomoses need to be done further distally into small diameter vessels with poorer run offs.

e) Drug eluting stents reduce restenosis at the high cost of late in-stent thrombosis with its attendant high mortality, particularly when associated with not taking anti platelet therapy as during postoperative period [105].

f) Patients with PCI require anti platelet agents which increase bleeding during surgery which increases mortality.

\section{Consent}

All patients undergoing revascularisation should have written informed consent unless patient is unstable or unable to consent as in cardiogenic shock or STEMI. In general, the previous practice of diagnostic coronary angiography proceed angioplasty should be frowned upon except when primary PCI is undertaken in STEMI or cardiogenic shock. This is to afford sufficient time to the patients for processing the information given to them and to reflect on the various therapeutic options available to them.

There is evidence to suggest that many patients undergoing both CABG and PCI have poor understanding of their disease, its management and of complications of any intervention, making true informed consent a difficult process, despite the desire of patients to be informed of all risks. PCI patients were found to be particularly optimistic regarding need for intervention over time, and therefore this issue needs specific attention during consent process. Medical staff too sometimes show an insufficient knowledge of the concepts of material risk and medical negligence, requiring improved efforts at not just patient education but also improved awareness on the part of both junior doctors and specialists [192].

Cardiac risk stratification models, not without their limitations as discussed earlier, should be central to not just guide medical decision-making but particularly to informed consent. It is good practice to inform patients about risks of intervention not just as determined by various risk-stratification models in use but also the risks of intervention as they are present in the particular institution and with the particular interventionists or surgeons, particularly if significantly different from the national average. It is reasonable for patients to expect that the surgeon or interventionist who will perform the major portion of the surgery or intervention will be personally involved in the consent process $[193,194]$.

\section{Conclusion}

A. CABG is the gold standard for revascularisation for all patients with complex coronary artery disease, particularly triple vessel, left main stem and proximal LAD disease.

B. Patients with focal single or double vessel disease involving arteries other than LAD, or mid or distal LAD disease should undergo PCI, unless myocardial ischaemia extends to large myocardial territories.

C. In patients with less complex triple vessel disease, as suggested by SYNTAX score <22, PCI after Heart Team or MDT discussion is an option, particularly if surgical risk is high. In patients with ostial and/or mid-shaft left main coronary artery stenosis, PCI is an alternative option, particularly if surgical risk is high. Patients with left main coronary artery stenosis involving distal bifurcation with or without single, double and even less complex triple vessel disease, with SYNTAX score $<32$, particularly when associated with high surgical risk, can undergo PCI after MDT or Heart Team discussion. 
D. Patients with risk factors that materially increase the risk of death and major morbidity from CABG, like severe dementia, severe uncorrectable neurological disease or conditions that increase the stroke risk, severe pulmonary disease and severe renal insufficiency, do not do well after CABG and consideration ought to be given to PCI.

E. Patients with history of diabetes, history of bleeding diathesis or GI bleeding, contraindications to dual-antiplatelet use, poor follow-up access, and those unwilling to accept the risk of repeat revascularisation, should undergo CABG.

F. Patients needing concomitant valvular and aortic surgery, with left ventricular dysfunction, and with coronary disease associated with chronic occlusions and bifurcation lesions and high SYNTAX scores should undergo CABG.

G. Decisions regarding choice of revascularisation, in chronic stable angina and ACS/NSTEMI, unless obvious, as in single or double vessel coronary disease not involving LAD (PCI) or complex coronary artery disease with high SYNTAX scores (>33), as in triple vessel disease or distal bifurcation left main stem disease with single, double or triple vessel disease (CABG), should be deferred to a Heart team or multidisciplinary team comprising at least a surgeon, an interventional and a non-interventional cardiologist.

H. There is good clinical trial-based evidence that FFRguided revascularisation improves long-term outcomes. In chronic stable coronary artery disease, there should be FFR estimation for all intermediate lesions of $50-70 \%$ stenosis and severe lesions of $70-90 \%$ stenosis; PCI should be undertaken if FFR is less than 0.8 and medical treatment continued if FFR is greater than 0.8. FFR is not recommended in lesions with $>90 \%$ stenosis. In unstable angina/ACS, whilst FFR is not recommended in the culprit lesion, in the non-culprit lesion, an FFR $<0.8$ warrants revascularisation.

I. All patients with acute STEMI should have primary emergency PCI to the coronary artery mostlikely to have caused STEMI. All patients with mechanical complications of STEMI including post-infarction VSD, acute mitral incompetence due to papillary muscle rupture or left or right ventricular rupture with tamponade are at considerable risk of dying without an operation and should have high risk immediate surgery unless outcomes are deemed to be hopeless. Patients with STEMI and critical left main stem stenosis not amenable to PCI, or those with continuing ischaemia of large myocardial territories not amenable to PCI usually require urgent CABG. CABG in patients who are otherwise suitable for primary PCI has worse outcomes.

J. Patients with NSTEMI OR ACS should have urgent revascularisation within 24 to 72 hours ideally but more realistically within a week. Evidence of ongoing ischaemia like chest pain, dynamic ECG changes and rising troponin levels should prompt immediate intervention.
K. Patients with stable coronary artery disease without severe symptoms should have a revascularisation procedure within 6 weeks. Revascularisation should be performed more expeditiously, within 2 weeks or so, if symptoms are severe, if coronary anatomy is dangerously compromised or if ventricular function is significantly depressed.

L. Off-pump surgery has excellent results in the hands of surgeons and institutions that routinely perform off-pump surgery. However, there is increasing evidence that the number and quality of grafts and, therefore, the long-term outcomes may be inferior to on-pump CABG. In patients with calcified ascending aorta, on the other hand, off-pump surgery can be life-saving.

M. There is no incontrovertible evidence to suggest that arterial grafts other than LIMA to LAD improve long-term survival. This may have more to do with the individual coronary artery run-off and the myocardial segments each coronary artery subtends rather than purely to the nature of conduit. Run-off in a graft and therefore its long-term patency largely depends on the run-off in the recipient myocardium.

\section{References}

1. The Veterans Administration Coronary Artery Bypass Surgery Group (1984) Eleven-year survival in the veterans administration randomized trial of coronary bypass surgery for stable angina. $\mathrm{N}$ Engl J Med 311(21): 1333-1339.

2. The VA Coronary Artery Bypass Surgery Cooperative Study Group (1992) Eighteen-year follow-up in the veterans affairs cooperative study of coronary artery bypass surgery for stable angina. Circulation 86(1): 21-30.

3. Peduzzi P, Kamina A, Detre K (1998) Twenty-two-year follow-up in the VA cooperative study of coronary artery bypass surgery for stable angina. Am J Cardiol 81(12): 1393-1399.

4. Detre KM, Takaro T, Hultgren H, Peduzzi P (1985) Long-term mortality and morbidity results of the veterans administration randomized trial of coronary artery bypass surgery. Circulation 72 (6 Pt 2): V84-V89.

5. Alderman EL, Bourassa MG, Cohen LS, Davis KB, Kaiser GG, et al. (1990) Ten-year follow-up of survival and myocardial infarction in the randomized coronary artery surgery study. Circulation 82(5): 16291646.

6. Chaitman BR, Fisher LD, Bourassa MG, Davis K, Rogers WJ, et al. (1981) Effect of coronary bypass surgery on survival patterns in subsets of patients with left main coronary artery disease. Report of the collaborative study in coronary artery surgery (CASS). Am J Cardiol 48(4): 765-777.

7. Passamani E, Davis KB, Gillespie MJ, Killip T (1985) A randomized trial of coronary artery bypass surgery. Survival of patients with a low ejection fraction. N Engl J Med 312(26): 1665-1671.

8. Killip T, Passamani E, Davis K (1985) Coronary artery surgery study (CASS): a randomized trial of coronary bypass surgery. Eight years follow-up and survival in patients with reduced ejection fraction. Circulation 72(6 Pt 2): V102-V109.

9. Varnauskas E (1998) Twelve-year follow-up of survival in the randomized European coronary surgery study. N Engl J Med 319(6): 332-337.

10. Yusuf S, Zucker D, Peduzzi P, Fisher LD, Takaro T, et al. (1994) Effect of coronary artery bypass graft surgery on survival: overview of 10-year results from randomised trials by the coronary artery bypass graft surgery trialists collaboration. Lancet 344(8922): 563-570. 


\section{Journal of Cardiology \& Cardiovascular Therapy}

11. Gruntzig AR, Senning A, Siegenthaler WE (1979) Nonoperative dilatation of coronary artery stenosis-percutaneous transluminal coronary angioplasty. N Eng J Med 301(2): 61-68.

12. King SB, Lembo NJ, Weintraub WS, Kosinski AS, Barnhart HX, et al. (1994) A randomised trial comparing coronary angioplasty with coronary bypass surgery. N Eng J Med 331(16): 1044-1050.

13. RITA Trial Participants (1993) Coronary angioplasty versus coronary artery bypass surgery: the randomised intervention treatment of angina (RITA) trial. The Lancet 341(8845): 573-580.

14. Rupprecht HJ, Hamm C, Ischinger T, Dietz U, Reimers J, et al. (1996) Anngiographic follow-up results of a randomised study on angioplasty versus bypass surgery (GABI trial). Eur Heart J 17(8): 1192-1198.

15. The BARI Investigators (2000) Seven-year outcome in the bypass angioplasty revascularisation investigation (BARI) by treatment and diabetic status. Journal of the American College of Cardiology 35(5) 1122-1129.

16. Serruys PW, Unger F, van Hout BA, van den Brand MJ, van Herwerden LA, et al. (1999) The ARTS study (arterial revascularisation therapies study). Semin Interv Cardiol 4(4): 209-219.

17. Rodriguez A, Bernardi V, Navia J, Baldi J, Grinfeld L, et al. (2001) Argentine randomised study: coronary angioplasty with stenting versus coronary bypass surgery in patients with multiple-vesse disease (ERACI II): 30-day and one-year follow-up results. ERACI II Investigators. J Am Coll Cardiol 37(1): 51-58.

18. Hueb W, Soares PR, Gersh BJ, César LA, Luz PL, et al. (2004) The medicine, angioplasty and surgery study (MASS-II): a randomised controlled clinical trial of three therapeutic strategies for multivesse coronary artery disease: one year results. J Am Coll Cardiol 43(10): 1743-1751.

19. SoS Investigators (2002) Coronary artery bypass surgery versus percutaneous coronary intervention with stent implantation in patients with multivessel coronary artery disease (the Stent or Surgery trial): a randomised controlled trial. Lancet 360(9338): 965-970.

20. Daemen J, Boersma E, Flather M, Booth J, Stables R, et al. (2008) Long term safety and efficacy of percutaneous coronary intervention with stenting and coronary artery bypass surgery for multivessel coronary artery disease: a meta-analysis with 5-year patient-level data from the ARTS, ERACI-II, MASS-II and SOS trials. Circulation 118(11): 1146 1154.

21. Bravata DM, Gienger AL, McDonald KM, Sundaram V, Perez MV, et al. (2007) Systematic review: the comparative effectiveness of percutaneous coronary interventions and coronary artery bypass graft surgery. Ann Intern Med 147(10): 703-716.

22. Bakhai A, Hill RA, Dundar Y, Dickson R, Walley T (2005) Percutaneous transluminal coronary angioplasty with stents versus coronary artery bypass grafting for people with stable angina or acute coronary syndromes. Cochrane Database Syst Rev (1): CD004588.

23. Hoffman SN, TenBrook JA, Wolf MP, Pauker SG, Salem DN, et al. (2003) A meta-analysis of randomized controlled trials comparing coronary artery bypass graft with percutaneous transluminal coronary angioplasty: one-to eight-year outcomes. J Am Coll Cardiol 41(8): 1293-1304

24. Morrison DA, Sethi G, Sacks J, Henderson WG, Grover F, et al. (2002) Percutaneous coronary intervention versus bypass surgery for patients with medically refractory myocardial ischaemia: AWESOME randomised trial and registry experience with post-CABG patients. Am Coll Cardiol 40(11): 1951-1954.

25. Daemen J, Boersma E, Flather M, Booth J, Stables R, et al. (2008) Long term safety and efficacy of PCI in stenting and CABG for multivesse CABG: a meta-analysis with 5 year data for ARTS, ERACI II, MASSII and SOS trials. Circulation 118(11): 1146-1154.

26. Taggart DP (2006) Controversies in cardiology. The Lancet 367(9519): 1313.

27. Brener SJ, Lytle BW, Casserly IP, Schneider JP, Topol EJ, et al. (2004) Propensity analysis of long-term survival after surgical or percutaneous revascularization in patients with multivessel coronary artery disease and high-risk features. Circulation 109(19): 2290-2295.

28. Hannan EL, Racz MJ, Walford G, Jones RH, Ryan TJ, et al. (2005) Long-term outcomes of coronary-artery bypass grafting versus stent implantation. N Engl J Med 352(21): 2174-2183.

29. Malenka DJ, Leavitt BJ, Hearne MJ, Robb JF, Baribeau YR, et al. (2005) Comparing long-term survival of patients with multivessel coronary disease after CABG or PCI: analysis of BARI-like patients in northern New England. Circulation 112(9 Suppl): I371-1376.

30. Smith PK, Califf RM, Tuttle RH, Shaw LK, Lee KL, et al. (2006) Selection of surgical or percutaneous coronary intervention provides differential longevity benefit. Ann Thorac Surg 82(4): 1420-1428.

31. Bair TL, Muhlestein JB, May HT, Meredith KG, Horne BD, et al. (2007) Surgical revascularization is associated with improved long-term outcomes compared with percutaneous stenting in most subgroups of patients with multivessel coronary artery disease: results from the Intermountain Heart Registry. Circulation 116(11 Suppl): 1226-1231.

32. Hannan EL, Wu C, Walford G, Culliford AT, Gold JP, et al. (2008) Drugeluting stents vs coronary-artery bypass grafting in multivessel coronary disease. N Engl J Med 358(4): 331-341.

33. Niles NW, McGrath PD, Malenka D, Quinton H, Wennberg D, et al (2001) Survival of patients with diabetes and multivessel coronary artery disease after surgical or percutaneous coronary revascularization: results of a large regional prospective study. J Am Coll Cardiol 37(4): 1008-1015.

34. Pell JP, Pell AC, Jeffrey RR, Jennings K, Oldroyd K, et al. (2004) Comparison of survival following coronary artery bypass grafting vs percutaneous coronary intervention in diabetic and non-diabetic patients: retrospective cohort study of 6320 procedures. Diabet Med 21(7): 790-792.

35. Gibbons RJ, Abrams J, Chatterjee K, Daley J, Deedwania PC, et al. (2003) ACC/AHA 2002 guideline update for the management of patients with chronic stable angina-summary article: a report of the American college of cardiology/American heart association task force on practice guidelines (Committee on the management of patients with chronic stable angina). J Am Coll Cardiol 41(1): 159-168.

36. Head SJ, Davierwala PM, Serruys PW, Redwood SR, Colombo A, et al. (2014) Coronary artery bypass grafting vs. percutaneous coronary intervention for patients with three-vessel disease: final five-year follow-up of the SYNTAX trial. Eur Heart J 35(40): 2821-2830.

37. OECD (2015) Health at a glance 2015. OECD Indicators. OECD Publishing, Paris, France.

38. Deutscher Herzbericht (2016) DGK, DGTHG, DGPK. Deutsche Herzstiftung e. V. Publishing: Frankfurt am Main, Germany.

39. Beckmann A, Funkat AK, Levandowski J, Frie M, Ernst M, et al. (2015) Cardiac surgery in Germany during 2014: a report on behalf of the German society for thoracic and cardiovascular. Thorac Cardiovasc Surg 63(4): 258-269.

40. Kolh P, Windecker S, Alfonso F, Collet JP, Cremer J, et al. (2014) ESC/ EACTS guidelines on myocardial revascularisation: the task force on myocardial revascularisation of the European Society of Cardiology (ESC) and the European association for cardio-thoracic surgery (EACTS). Developed with the special contribution of the European association of percutaneous cardiovascular interventions (EAPCI). EurJ Cardiothoracic Surg 46(4): 517-592.

41. Hilliis LD, Smith PK, Anderson JL, Bittl JA, Bridges CR, et al. (2011) AAF/ AHA guideline for coronary artery bypass graft surgery. A report of the American college of cardiology foundation/American heart association task force on practice guidelines. Developed in collaboration with the American association for thoracic surgery. Society of cardiovascular anaesthesiologists and society of thoracic surgeons. J Am Coll Cardio 58(24): e123-e210.

42. Fihn SD, Gardin JM, Abrams J, Berra K, Blankenship JC, et al. (2012) ACCF/AHA/ACP/AATS/PCNA/SCAL/STS guideline for the diagnosis and management of patients with stable ischaemic heart disease 
report of the American college of cardiology foundation/American heart association task force on practice guidelines, and the American college of physicians, American association of for thoracic surgery, preventive cardiovascular nurses association, society of cardiovascular angiography and interventions, and society of thoracic surgeons. J Am Coll Cardiol 60(24): e44-e164.

43. Fihn SD, Blankenship JC, Alexander KP, Bittl JA, Byrne JG, et al. (2014) ACC/AHA/AATS/PCNA/SCAI/STS focused update of the guideline for the diagnosis and management of patients with stable ischemic heart disease: a report of the American college of cardiology/American heart association task force on practice guidelines, and the American association for thoracic surgery, preventive cardiovascular nurses association, society for cardiovascular angiography and interventions, and society of thoracic surgeons. J Am Coll Cardiol 64(18): 1929-1949.

44. Feit F, Brooks MM, Sopko G, Keller NM, Rosen A, et al. (2000) Longterm clinical outcome in the bypass angioplasty revascularization investigation registry: comparison with the randomized trial. BARI Investigators. Circulation 101(24): 2795-2802.

45. King SB, Barnhart HX, Kosinski AS, Weintraub WS, Lembo NJ, et al (1997) Angioplasty or surgery for multivessel coronary artery disease: comparison of eligible registry and randomized patients in the EAST trial and influence of treatment selection on outcomes. Emory angioplasty versus surgery trial investigators. Am J Cardiol 79(11): 1453-1459.

46. Yates MT, Soppa GK, Valencia O, Jones S, Firoozi S, et al. (2014) Impact of European society of cardiology and European association for cardiothoracic surgery guidelines on myocardial revascularization on the activity of percutaneous coronary intervention and coronary artery bypass graft surgery for stable coronary artery disease. J Thorac Cardiovasc Surg 147(2): 606-610.

47. Long J, Luckraz H, Thekkudan J, Maher A, Norell M (2012) Heart team discussion in managing patients with coronary artery disease: outcome and reproducibility. Interact Cardiovasc Thorac Surg 14(5): 594-598.

48. Bonzel T, Schachinger V, Dorge H (2015) Description of a heart team approach to coronary revascularization and its beneficial long-term effect on clinical events after PCI. Clin Res Cardiol 105(5): 388-400.

49. Fraker TD, Fihn SD, Gibbons RJ, Abrams J, Chatterjee K, et al. (2007) Chronic angina focused update of the ACC/AHA 2002 guidelines for the management of patients with chronic stable angina: a report of the American College of Cardiology/American Heart Association Task Force on practice guidelines writing group to develop the focused update of the 2002 guidelines for the management of patients with chronic stable angina. J Am Coll Cardiol 50(23): 2264-2274.

50. Anderson JL, Adams CD, Antman EM, Bridges CR, Califf RM, et al. (2007) ACC/AHA 2007 guidelines for the management of patients with unstable angina/non-ST-Elevation myocardial infarction: a report of the American College of Cardiology/American Heart Association Task Force on practice guidelines (Writing committee to revise the 2002 guidelines for the management of patients with unstable Angina/Non-ST-Elevation myocardial infarction) developed in collaboration with the American College of Emergency Physicians, the society for cardiovascular angiography and interventions, and the society of thoracic surgeons endorsed by the American association of cardiovascular and pulmonary rehabilitation and the society for academic emergency medicine. Circulation 116(7): e148-e304.

51. Patel MR, Dehmer GJ, Hirshfeld JW, Smith PK, Spertus JA (2009) ACCF/SCAI/STS/AATS/AHA/ASNC 2009 appropriateness criteria for coronary revascularization: a report of the American college of cardiology foundation appropriateness criteria task force, society for cardiovascular angiography and interventions, society of thoracic surgeons, American association for thoracic surgery, American heart association, and the American society of nuclear cardiology: endorsed by the American society of echocardiography, the heart failure society of America, and the society of cardiovascular computed tomography. J Am Coll Cardiol 53(6): 530-553.

52. Serruys PW, Morice MC, Kappetein AP, Colombo A, Holmes DR, et al. (2009) Percutaneous coronary intervention versus coronary-artery bypass grafting for severe coronary artery disease. N Engl J Med 360(10): 961-972.

53. Aldea GS, Bakaeen FG, Pal J, Fremes S, Head S, et al. (2016) The society of thoracic surgeons clinical practice guidelines on arterial conduits for coronary artery bypass grafting. Ann Thorac Surg 101(2): 801-809.

54. O'Gara PT, Kushner FG, Ascheim DD, Casey DE, Chung MK, et al. (2013) 2013 ACCF/AHA guideline for the management of ST-elevation myocardial infarction: a report of the American College of Cardiology Foundation/American Heart Association Task Force on practice guidelines. Circulation 127(4): e362-e425.

55. Schwartz RS, Edwards WD, Huber KC, Antoniades LC, Bailey KR, et al. (1993) Coronary restenosis: prospects for solution and new perspectives from a porcine model. Mayo Clin Proc 68(1): 54-62.

56. Schwartz RS, Holmes DR, Topol EJ (1992) The restenosis paradigm revisited: an alternative proposal for cellular mechanisms. J Am Coll Cardiol 20(5): 1284-1293.

57. Brophy JM, Belisle P, Joseph L (2003) Evidence for use of coronary stents. A hierarchical bayesian meta-analysis. Ann Intern Med 138(10): 777-786.

58. Fischman DL, Leon MB, Baim DS, Schatz RA, Savage MP, et al. (1994) A randomized comparison of coronary-stent placement and balloon angioplasty in the treatment of coronary artery disease. Stent Restenosis Study Investigators. N Engl J Med 331(8): 496-501.

59. Serruys PW, de Jaegere P, Kiemeneij F, Macaya C, Rutsch W, et al. (1994) A comparison of balloon-expandable-stent implantation with balloon angioplasty in patients with coronary artery disease. Benestent study group. N Engl J Med 331(8): 489-495.

60. Sousa JE, Costa MA, Abizaid AC, Rensing BJ, Abizaid AS, et al. (2001) Sustained suppression of neointimal proliferation by sirolimus-eluting stents: one-year angiographic and intravascular ultrasound follow-up. Circulation 104(17): 2007-2011.

61. Stone GW, Moses JW, Ellis SG, Schofer J, Dawkins KD, et al. (2007) Safety and efficacy of sirolimus-and paclitaxel-eluting coronary stents. N Engl J Med 356(10): 998-1008.

62. Stettler C, Wandel S, Allemann S, Kastrati A, Morice MC, et al. (2007) Outcomes associated with drug-eluting and bare-metal stents: a collaborative network meta-analysis. Lancet 370(9591): 937-948.

63. Abbott JD, Voss MR, Nakamura M, Cohen HA, Selzer F, et al. (2007) Unrestricted use of drug-eluting stents compared with bare-metal stents in routine clinical practice: findings from the National Heart, Lung, and Blood Institute Dynamic Registry. J Am Coll Cardiol 50(21): 2029-2036.

64. Marroquin OC, Selzer F, Mulukutla SR, Williams DO, Vlachos HA, et al. (2008) A comparison of bare-metal and drug-eluting stents for offlabel indications. N Engl J Med 358(4): 342-352.

65. Ardissino D, Cavallini C, Bramucci E, Indolfi C, Marzocchi A, et al. (2004) Sirolimus-eluting vs uncoated stents for prevention of restenosis in small coronary arteries: a randomized trial. JAMA 292(22): 2727 2734.

66. Degertekin M, Arampatzis CA, Lemos PA, Saia F, Hoye A, et al. (2004) Very long sirolimus-eluting stent implantation for de novo coronary lesions. Am J Cardiol 93(7): 826-829.

67. Migliorini A, Moschi G, Vergara R, Parodi G, Carrabba N, et al. (2006) Drug-eluting stent-supported percutaneous coronary intervention for chronic total coronary occlusion. Catheter Cardiovasc Interv 67(3): 344-348.

68. Nakamura S, Muthusamy TS, Bae JH, Cahyadi YH, Udayachalerm W, et al. (2005) Impact of sirolimus-eluting stent on the outcome of patients with chronic total occlusions. Am J Cardiol 95(2): 161-166.

69. Pasceri V, Patti G, Speciale G, Pristipino C, Richichi G, et al. (2007) Metaanalysis of clinical trials on use of drug-eluting stents for treatment of acute myocardial infarction. Am Heart J 153(5): 749-754. 
70. Sabate M, Jimenez QP, Angiolillo DJ, Gomez HJA, Alfonso F, et al. (2005) Randomized comparison of sirolimus-eluting stent versus standard stent for percutaneous coronary revascularization in diabetic patients: the diabetes and sirolimus-eluting stent (DIABETES) trial. Circulation 112(14): 2175-2183.

71. Schampaert E, Cohen EA, Schluter M, Reeves F, Traboulsi M, et al. (2004) The Canadian study of the sirolimus-eluting stent in the treatment of patients with long de novo lesions in small native coronary arteries (C-SIRIUS). J Am Coll Cardiol 43(6): 1110-1115.

72. Schofer J, Schluter M, Gershlick AH, Wijns W, Garcia E, et al. (2003) Sirolimus-eluting stents for treatment of patients with long atherosclerotic lesions in small coronary arteries: double-blind, randomised controlled trial (E-SIRIUS). Lancet 362(9390): 1093-1099.

73. Werner GS, Krack A, Schwarz G, Prochnau D, Betge S, et al. (2004) Prevention of lesion recurrence in chronic total coronary occlusions by paclitaxel-eluting stents. J Am Coll Cardiol 44(12): 2301-2306.

74. Kumbhani DJ, Bavry AA, Kamdar AR, Helton TJ, Bhatt DL (2008) The effect of drug-eluting stents on intermediate angiographic and clinica outcomes in diabetic patients: insights from randomized clinical trials. Am Heart J 155(4): 640-647.

75. Ge L, Iakovou I, Sangiorgi GM, Chieffo A, Melzi G, et al. (2005) Treatment of saphenous vein graft lesions with drug-eluting stents: immediate and midterm outcome. J Am Coll Cardiol 45(7): 989-994.

76. Mauri L, Hsieh WH, Massaro JM, Ho KK, D’Agostino R, et al. (2007) Stent thrombosis in randomized clinical trials of drug-eluting stents. N Engl J Med 356(10): 1020-1029.

77. Bavry AA, Kumbhani DJ, Helton TJ, Borek PP, Mood GR, et al. (2006) Late thrombosis of drug-eluting stents: a meta-analysis of randomized clinical trials. Am J Med 119(12): 1056-1061.

78. Byrne RA, Kastrati A, Kufner S, Massberg S, Birkmeier KA, et al. (2009) Randomized, non-inferiority trial of three limus agent-eluting stents with different polymer coatings: the Intracoronary Stenting and Angiographic Results: Test Efficacy of 3 Limus- Eluting Stents (ISARTEST-4) Trial. Eur Heart J 30(20): 2441-2449.

79. Windecker S, Serruys PW, Wandel S, Buszman P, Trznadel S, et al. (2008) Biolimus- eluting stent with biodegradable polymer versus sirolimuseluting stent with durable polymer for coronary revascularisation (LEADERS): a randomised non-inferiority trial. Lancet 372(9644): 1163-1173.

80. Mehilli J, Byrne RA, Wieczorek A, Iijima R, Schulz S, et al. (2008) Randomized trial of three rapamycin-eluting stents with different coating strategies for the reduction of coronary restenosis. Eur Heart J 29(16): 1975-1982.

81. Stefanini GG, Byrne RA, Serruys PW, de Waha A, Meier B, et al. (2012) Biodegradable polymer drug-eluting stents reduce the risk of stent thrombosis at 4 years in patients undergoing percutaneous coronary intervention: a pooled analysis of individual patient data from the ISAR-TEST 3, ISAR-TEST 4, and LEADERS randomized trials. Eur Heart J 33(10): 1214-1222.

82. de Waha A, Stefanini GG, King LA, Byrne RA, Serruys PW, et al. (2013) Long-term outcomes of biodegradable polymer versus durable polymer drug-eluting stents in patients with diabetes a pooled analysis of individual patient data from 3 randomized trials. Int J Cardiol 168(6): 5162-5166.

83. Adjedj J, Toth GG, Johnson NP, Pellicano M, Ferrara A, et al. (2015) Intracoronary adenosine: dose-response relationship with hyperemia. JACC Cardiovasc Interv 8(11): 1422-1430.

84. Christou MA, Siontis GC, Katritsis DG, Ioannidis JP (2007) Meta-analysis of fractional flow reserve versus quantitative coronary angiography and noninvasive imaging for evaluation of myocardial ischemia. Am J Cardiol 99(4): 450-456.

85. Tonino PA, De Bruyne B, Pijls NH, Siebert U, Ikeno F, et al. (2009) Fractional flow reserve versus angiography for guiding percutaneous coronary intervention. N Engl J Med 360(3): 213-224.
86. Dattilo PB, Prasad A, Honeycutt E, Wang TY, Messenger JC (2012) Contemporary patterns of fractional flow reserve and intravascular ultrasound use among patients undergoing percutaneous coronary intervention in the United States: insights from the national cardiovascular data registry. J Am Coll Cardiol 60(22): 2337-2339.

87. Sen S, Escaned J, Malik IS, Mikhail GW, Foale RA, et al. (2012) Development and validation of a new adenosine-independent index of stenosis severity from coronary wave-intensity analysis: results of the ADVISE (Adenosine Vasodilator Independent Stenosis Evaluation) study. J Am Coll Cardiol 59(15): 1392-1402.

88. Jeremias A, Maehara A, Généreux P, Asrress KN, Berry C, et al. (2014) Multicenter core laboratory comparison of the instantaneous wavefree ratio and resting $\mathrm{Pd} / \mathrm{Pa}$ with fractional flow reserve: the RESOLVE study. J Am Coll Cardiol 63(13): 1253-1261.

89. Hwang D, Jeon KH, Lee JM, Park J, Kim CH, et al. (2017) Diagnostic performance of resting and hyperemic invasive physiological indices to define myocardial ischemia: validation with $13 \mathrm{~N}$-Ammonia positron emission tomography. JACC Cardiovasc Interv 10(8): 751-760.

90. Götberg M, Christiansen EH, Gudmundsdottir IJ (2017) Instantaneous wave-free ratio versus fractional flow reserve to guide PCI. N Engl J Med 376: 1813-1823.

91. Davies JE, Sen S, Dehbi HM (2017) Use of the instantaneous wave-free ratio or fractional flow reserve in PCI. N Engl J Med 376: 1824-1834.

92. Pijls NH, van Schaardenburgh P, Manoharan G, Boersma E, Bech JW, et al. (2007) Percutaneous coronary intervention of functionally nonsignificant stenosis: 5-year follow-up of the DEFER Study. J Am Coll Cardiol 49(21): 2105-2111.

93. De Bruyne B, Pijls NH, Kalesan B (2012) Fractional flow reserveguided PCI versus medical therapy in stable coronary disease. N Engl J Med 367: 991-1001.

94. De Bruyne B, Fearon WF, Pijls NH (2014) Fractional flow reserveguided PCI for stable coronary artery disease. N Engl J Med 371: 12081217.

95. Muller O, Mangiacapra F, Ntalianis A, Verhamme KM, Trana C, et al. (2011) Long-term follow-up after fractional flow reserve-guided treatment strategy in patients with an isolated proximal left anterior descending coronary artery stenosis. JACC Cardiovasc Interv 4(11): 1175-1182.

96. Li J, Elrashidi MY, Flammer AJ, Lennon RJ, Bell MR, et al. (2013) Longterm outcomes of fractional flow reserve-guided vs. angiographyguided percutaneous coronary intervention in contemporary practice. Eur Heart J 34: 1375-1383.

97. Van Belle E, Rioufol G, Pouillot C, Cuisset T, Bougrini K, et al. (2014) Outcome impact of coronary revascularization strategy reclassification with fractional flow reserve at time of diagnostic angiography: insights from a large French multicenter fractional flow reserve registry. Circulation 129(2): 173-185.

98. Curzen N, Rana O, Nicholas Z, Golledge P, Zaman A, et al.(2014) Does routine pressure wire assessment influence management strategy at coronary angiography for diagnosis of chest pain?: the RIPCORD study. Circ Cardiovasc Interv 7(2): 248-255.

99. Engstrøm T, Kelbæk H, Helqvist S (2015) Complete revascularisation versus treatment of the culprit lesion only in patients with ST-segment elevation myocardial infarction and multi vessel disease (DANAMI-3 PRIMULTI): an open-label, randomised controlled trial. Lancet 386(9994): 665-671.

100. Smits PC, Abdel-Wahab M, Neumann FJ (2017) Fractional flow reserve-guided multi vessel angioplasty in myocardial infarction. $\mathrm{N}$ Engl J Med 376: 1234-1244.

101. Ahn JM, Park DW, Shin ES, Koo BK, Nam CW, et al. (2017) Fractional flow reserve and cardiac events in coronary artery disease: data from a prospective registry (interventional cardiology research incooperation society fractional flow reserve). Circulation 135(23): 2241-2251. 
102. Lotfi A, Jeremias A, Fearon WF, Feldman MD, Mehran R, et al. (2014) Expert consensus statement on the use of fractional flow reserve, intravascular ultrasound, and optical coherence tomography: a consensus statement of the society of cardiovascular angiography and interventions. Catheter Cardiovasc Interv 83(4): 509-518.

103. Shlofmitz E, Jeremias A (2017) American College of Cardiology Expert Analysis.

104. Barner HB (2008) Operative treatment of coronary atherosclerosis. Ann Thorac Surg 85(4): 1473-1482.

105. Kobayashi J (2008) Current status of coronary artery bypass grafting. Gen Thorac Cardiovasc Surg 56(6): 260-267.

106. Cheng DC, Bainbridge D, Martin JE, Novick RJ (2005) Evidencebased perioperative clinical outcomes research group. Does offpump coronary artery bypass reduce mortality, morbidity, and resource utilization when compared with conventional coronary artery bypass? A meta-analysis of randomized trials. Anesthesiology 102(1): 188-203.

107. Nalysnyk L, Fahrbach K, Reynolds MW, Zhao SZ, Ross S (2003) Adverse events in coronary artery bypass graft (CABG) trials: a systematic review and analysis. Heart 89(7): 767-772.

108. Bridgewater B, Keogh B (2008) Sixth national adult cardiac surgical database report. p. 52.

109. Wan S, LeClerc JL, Vincent JL (1997) Inflammatory response to cardiopulmonary bypass: mechanisms involved and possible therapeutic strategies. Chest 112(3): 676-692.

110. Matata BM, Sosnowski AW, Galinanes M (2000) Off-pump bypass graft operation significantly reduces oxidative stress and inflammation. Ann Thorac Surg 69(3): 785-791.

111. Okubo N, Hatori N, Ochi M, Tanaka S (2003) Comparison of m-RNA expression for inflammatory mediators in leukocytes between onpump and off-pump coronary artery bypass grafting. Ann Thorac Cardiovasc Surg 9(1): 43-49.

112. Chowdhury UK, Malik V, Yadav R, Seth S, Ramakrishnan L(2008) Myocardial injury in coronary artery bypass grafting: On-pump versus on-pump comparison by measuring high-sensitivity C-reactive protein, cardiac troponin I, heart-type fatty acid-binding protein, creatinine kinase MB and myoglobin release. The Journal of Thoracic and Cardiovascular Surgery 135(5): 1110-1120.

113. Feng ZZ, Shi J, Zhao XW, Xu ZF (2009) Meta-analysis of on-pump and off-pump coronary arterial revascularization. Ann Thorac Surg 87(3): 757-765.

114. Reston JT, Tregear SJ, Turkelson CM (2003) Meta-analysis of shortterm and mid-term outcomes following off-pump coronary artery bypass grafting. Ann Thorac Surg 76(5): 1510-1515.

115. Sellke FW, Di Maio JM, Caplan LR, Ferguson TB, Gardner TJ, et al. (2005) Comparing on-pump and off-pump coronary artery bypass grafting: numerous studies but few conclusions: a scientific statement from the American Heart Association council on cardiovascular surgery and anesthesia in collaboration with the interdisciplinary working group on quality of care and outcomes research. Circulation 111(21): 2858-2864.

116. Shroyer LA, Grover FL, Hattler B, Collins JF, et al. (2009) On-pump versus off-pump coronary bypass surgery. The New England Journal of Medicine 361: 1827-1837.

117. Diegeler A, Borgermann J, Kappert U, Breuer M, Boning A, et al. (2013) Off-pump versus on-pump coronary-artery bypass grafting in elderly patients. N Engl J Med 368(13): 1189-1198.

118. Houlind K, Kjeldsen BJ, Madsen SN, Rasmussen BS, Holme SJ, et al. (2012) On-pump versus off-pump coronary artery bypass surgery in elderly patients: results from the Danish on-pump versus off-pump randomisation study. Circulation 125(20): 2431-2439.

119. Lamy A, Devereaux PJ, Prabhakaran D, Taggart DP, Hu S, et al. (2013) Effects of off-pump and on-pump coronary-artery bypass grafting at 1 year. N Engl J Med 368(13): 1179-1188.
120. Zhang B, Zhou J, Li H, Liu Z, Chen A, et al. (2014) Comparison of graft patency between off-pump and on-pump coronary artery bypass grafting: an updated meta-analysis. Ann Thorac Surg 97(4): 13351341.

121. Takagi H, Umemoto $\mathrm{T}$ (2014) Worse long-term survival after offpump than on-pump coronary artery bypass grafting. J Thorac Cardiovasc Surg 148(5): 1820-1829.

122. Lytle BW, Loop FD, Cosgrove DM, Ratliff NB, Easley K, et al. (1985) Long-term ( 5 to 12 years) serial studies of internal mammary artery and saphenous vein coronary bypass grafts. J Thorac Cardiovasc Surg 89(2): 248-258.

123. Singh RN, Sosa JA, Green GE (1983) Long-term fate of the internal mammary artery and saphenous vein grafts. J Thorac Cardiovasc Surg 86(3): 359-363.

124. Tector AJ, Schmahl TM, Janson B, Kallies JR, Johnson G (1981) The internal mammary artery graft. Its longevity after coronary bypass. JAMA 246(19): 2181-2183.

125. Barner HB, Swartz MT, Mudd JG, Tyras DH (1982) Late patency of the internal mammary artery as a coronary bypass conduit. Ann Thorac Surg 34(4): 408-412.

126. Loop FD, Lytle BW, Cosgrove DM, Stewart RW, Goormastic M, et al. (1986) Influence of the internal-mammary-artery graft on 10-year survival and other cardiac events. N Engl J Med 314(1): 1-6.

127. Grondin CM, Campeau L, Lesperance J, Enjalbert M, Bourassa MG (1984) Comparison of late changes in internal mammary artery and saphenous vein grafts in two consecutive series of patients 10 years after operation. Circulation 70(3 Pt 2): 1208-1212.

128. Shah PJ, Durairaj M, Gordon I, Fuller J, Rosalion A, et al. ( 2004) Factors affecting patency of internal thoracic artery graft: clinical and angiographic study in 1434 symptomatic patients operated between 1982 and 2002. Eur J Cardiothorac Surg 26(1):118-124.

129. Lytle BW, Blackstone EH, Sabik JF, Houghtaling P, Loop FD, et al. (2004) The effect of bilateral internal thoracic artery grafting on survival during 20 postoperative years. Ann Thorac Surg 78(6): 2005-2014.

130. Burfeind WR, Glower DD, Wechsler AS, Tuttle RH, Shaw LK, et al. (2004) Single versus multiple internal mammary artery grafting for coronary artery bypass: 15-year follow-up of a clinical practice trial. Circulation 110(11): 1127-1135.

131. Taggart DP, D'Amico R, Altman DG (2001) Effect of arterial revascularisation on survival: a systematic review of studies comparing bilateral and single internal mammary arteries. Lancet 358 (9285): 870-875.

132. Yi G, Shine B, Rehman SM, Altman DG, Taggart DP (2014) Effect of bilateral internal mammary artery grafts on long-term survival: a meta-analysis approach. Circulation 130(7): 539-545.

133. Takagi H, Goto SN, Watanabe T, Mizuno Y, Kawai N, et al. (2014) A meta-analysis of adjusted hazard ratios from 20 observational studies of bilateral versus single internal thoracic artery coronary artery bypass grafting. J Thorac Cardiovasc Surg 148(4): 1282-1290.

134. Bakaeen FG, Chu D, Dhaliwal AS, Bozkurt B, Wang XL, et al. (2008) Does the use of bilateral internal mammary artery grafts impact survival of veterans undergoing coronary artery bypass surgery? Am J Surg 196(5): 726-731.

135. Taggart DP, Altman DG, Gray AM, Lees B, Gerry S, et al. (2016) Randomised trial of bilateral versus single internal internal thoracic artery grafts. N Engl J Med 375(26): 2540-2549.

136. Toumpoulis IK, Theakos N, Dunning J (2007) Does bilateral internal thoracic artery harvest increase the risk of mediastinitis? Interact Cardiovasc Thorac Surg 6(6): 787-791.

137. Nezic DG, Knezevic AM, Milojevic PS, Dukanovic BP, Jovic MD, et al. (2006) The fate of the radial artery conduit in coronary artery bypass grafting surgery. Eur J Cardiothorac Surg 30(2): 341-346. 
138. Zacharias A, Schwann TA, Riordan CJ, Durham SJ, Shah AS, et al. (2009) Late results of conventional versus all-arterial revascularization based on internal thoracic and radial artery grafting. Ann Thorac Surg 87(1): 19-26.

139. Miwa S, Desai N, Koyama T, Chan E, Cohen EA, et al. (2006) Radial artery angiographic string sign: clinical consequences and the role of pharmacologic therapy. Ann Thorac Surg 81(11): 112-118.

140. Navia D, Vrancic M, Vaccarino G, Piccinini F, Raich H, et al. (2008) Total arterial off-pump coronary revascularization using bilateral internal thoracic arteries in triple-vessel disease: surgical technique and clinical outcomes. Ann Thorac Surg 86(2): 524-530.

141. Kim WS, Lee J, Lee YT, Sung K, Yang JH, et al. (2008) Total arterial revascularization in triple-vessel disease with off-pump and aortic no-touch technique. Ann Thorac Surg 86(6): 1861-1865.

142. Fukui T, Takanashi S, Hosoda Y, Suehiro S (2005) Total arterial myocardial revascularization using composite and sequential grafting with the off-pump technique. Ann Thorac Surg 80(2): 579585.

143. Mariani MA, D’Alfonso A, Grandjean JG (2004) Total arterial off-pump coronary surgery: time to change our habits? Ann Thorac Surg 78(5): 159-167.

144. Tagusari O, Kobayashi J, Bando K, Niwaya K, Nakajima H, et al. (2004) Total arterial off-pump coronary artery bypass grafting for revascularization of the total coronary system: clinical outcome and angiographic evaluation. Ann Thorac Surg 78(4): 1304-1311.

145. Kobayashi J, Tagusari O, Bando K, Niwaya K, Nakajima H, et al. (2002) Total arterial off-pump coronary revascularization with only internal thoracic artery and composite radial artery grafts. Heart Surg Forum 6(1): 30-37.

146. Zacharias A, Schwann TA, Riordan CJ, Durham SJ, Shah AS, et al (2010) Late outcomes after radial artery versus saphenous vein grafting during reoperative coronary artery bypass surgery. J Thorac Cardiovasc Surg 139(6): 1511-1518.

147. Muneretto C, Bisleri G, Negri A, Manfredi J, Metra M, et al. (2003) Total arterial myocardial revascularization with composite grafts improves results of coronary surgery in elderly: a prospective randomized comparison with conventional coronary artery bypass surgery. Circulation 108(1): 1129-1133.

148. Buxton BF, Shi WY, Tatoulis J, Fuller JA, Rosalion A, et al. (2014) Total arterial revascularization with internal thoracic and radial artery grafts in triple-vessel coronary artery disease is associated with improved survival. J Thorac Cardiovasc Surg 148(4): 1238-1243.

149. Shi WY, Hayward PA, Tatoulis J, Rosalion A, Newcomb AE, et al. (2015) Are all forms of total arterial revascularization equal? A comparison of single versus bilateral internal thoracic artery grafting strategies. J Thorac Cardiovasc Surg 150(6): 1526-1534.

150. Kamiya H, Ushijima T, Kanamori T, Ikeda C, Nakagaki C, et al. (2003) Use of the radial artery graft after transradial catheterization: is it suitable as a bypass conduit? Ann Thorac Surg 76(5): 1505-1509.

151. Grau JB, Kuschner CE, Johnson CK, Ferrari G, Zapolanski A, et al. (2016) The effects of using a radial artery in patients already receiving bilateral internal mammary arteries during coronary bypass grafting: 30-day outcomes and 14-year survival in a propensity-matched cohort. Eur J Cardiothorac Surg 49(1): 203-210.

152. Glineur D (2013) Importance of the third arterial graft in multiple arterial grafting strategies. Ann Cardiothorac Surg 2(4): 475-480.

153. Guru V, Fremes SE, Tu JV (2006) How many arterial grafts are enough? A population-based study of midterm outcomes. J Thorac Cardiovasc Surg 131(5): 1021-1028.

154. Daemen J, Kuck KH, Macaya C, LeGrand V, Vrolix M, et al. (2008) Multivessel coronary revascularization in patients with and without diabetes mellitus: 3-year follow-up of the ARTS-II (Arterial Revascularization Therapies Study-Part II) trial. J Am Coll Cardiol 52(24): 1957-1967.
155. Hannan EL, Wu C, Walford G, Culliford AT, Gold JP, et al. (2008) Drugeluting stents vs. coronary-artery bypass grafting in multivessel coronary disease. N Engl J Med 358(4): 331-341.

156. Javaid A, Steinberg DH, Buch AN, Corso PJ, Boyce SW, et al. (2007) Outcomes of coronary artery bypass grafting versus percutaneous coronary intervention with drug-eluting stents for patients with multivessel coronary artery disease. Circulation 116(11): 12001206.

157. Kukreja N, Serruys PW, De Bruyne B, Colombo A, Macaya C, et al. (2009) Sirolimus-eluting stents, bare metal stents or coronary artery bypass grafting for patients with multivessel disease including involvement of the proximal left anterior descending artery: analysis of the Arterial Revascularization Therapies study part 2 (ARTS-II). Heart 95(13): 1061-1066.

158. Park DW, Yun SC, Lee SW, Kim YH, Lee CW, et al. (2008) Long-term mortality after percutaneous coronary intervention with drugeluting stent implantation versus coronary artery bypass surgery for the treatment of multivessel coronary artery disease. Circulation 117(16): 2079-2086.

159. Rodriguez AE, Maree AO, Mieres J, Berrocal D, Grinfeld L, et al. (2007) Late loss of early benefit from drug-eluting stents when compared with bare-metal stents and coronary artery bypass surgery: 3 years follow-up of the ERACI III registry. Eur Heart J 28(17): 2118-2125.

160. Serruys PW, Daemen J, Morice MC, de Bruyne B, Colombo A, et al. (2007) Three-year follow-up of the ARTS-II-sirolimus-eluting stents for the treatment of patients with multivessel coronary artery disease. Euro Intervention 3(4): 450-459.

161. Varani E, Balducelli M, Vecchi G, Aquilina M, Maresta A (2007) Comparison of multiple drug-eluting stent percutaneous coronary intervention and surgical revascularization in patients with multivessel coronary artery disease: one-year clinical results and total treatment costs. J Invasive Cardiol 19(11): 469-475.

162. Yang JH, Gwon HC, Cho SJ, Hahn JY, Choi JH, et al. (2008) Comparison of coronary artery bypass grafting with drug-eluting stent implantation for the treatment of multivessel coronary artery disease. Ann Thorac Surg 85(1): 65-70.

163. Serruys PW, Morice MC, Kappetein AP, Colombo A, Holmes DR, et al (2009) Percutaneous coronary intervention versus coronary-artery bypass grafting for severe coronary artery disease. N Engl J Med 360(10): 961-972.

164. Kappetein AP, Dawkins KD, Mohr FW, Morice MC, Mack MJ, et al. (2006) Current percutaneous coronary intervention and coronary artery bypass grafting practices for three-vessel and left main coronary artery disease. Insights from the SYNTAX run-in phase. Eur J Cardiothorac Surg 29(4): 486-491.

165. Taggart DP, Kaul S, Boden WE, Ferguson TB, Guyton RA, et al. (2008) Revascularization for unprotected left main stem coronary artery stenosis stenting or surgery. J Am Coll Cardiol 51(9): 885-892.

166. Chieffo A, Morici N, Maisano F, Bonizzoni E, Cosgrave J, et al. (2006) Percutaneous treatment with drug-eluting stent implantation versus bypass surgery for unprotected left main stenosis: a single-center experience. Circulation 113(21): 2542-2547.

167. Palmerini T, Marzocchi A, Marrozzini C, Ortolani P, Saia F, et al. (2006) Comparison between coronary angioplasty and coronary artery bypass surgery for the treatment of unprotected left main coronary artery stenosis (the Bologna Registry). Am J Cardiol 98(1): 54-59.

168. Valgimigli M, Malagutti P, Rodriguez-Granillo GA, Garcia-Garcia HM, Polad J, et al. (2006) Distal left main coronary disease is a major predictor of outcome in patients undergoing percutaneous intervention in the drug-eluting stent era: an integrated clinical and angiographic analysis based on the Rapamycin-Eluting Stent Evaluated at Rotterdam Cardiology Hospital (RESEARCH) and TaxusStent Evaluated at Rotterdam Cardiology Hospital (T-SEARCH) registries. J Am Coll Cardiol 47(8): 1530-1537.

169. Chieffo A, Park SJ, Valgimigli M, Kim YH, Daemen J, et al. (2007) Favorable long-term outcome after drug-eluting stent implantation 
in nonbifurcation lesions that involve unprotected left main coronary artery: a multicenter registry. Circulation 116(2): 158-162.

170. Buszman PE, Kiesz SR, Bocheneck A, Peszek-Przybyla E, Szkrobka I, et al. (2008) Acute and late outcomes of unprotected left main stem stenting in comparison with surgical revascularisation. J Am Coll Cardiol 51(5): 538-545.

171. Prius C, Jonker DDV, Botes L, Smit FE (2012) Cadiac surgery riskstratification models. Cardiovasc J Afr 23(3): 160-164.

172. Nashef SA, Roques F, Michel P, Gauducheau E, Lemeshow S, et al (1999) European system for cardiac operative risk evaluation (EuroSCORE). Eur J Cardiothorac Surg 16(1): 9-13.

173. Van Straten, Tan E, van Zundert AAJ, Hamad MA, Martens EJ (2010) Evaluation of Euro SCORE risk scoring model for patients undergoing coronary artery bypass grafting: a word of caution. Neth Heart J 18(7-8): 355-359.

174. Sianos G, Morel MA, Kappetein AP, Morice MC, Colombo A, et al. (2005) The SYNTAX Score: an angiographic tool grading the complexity of coronary artery disease. Euro Intervention 1(2): 219-227.

175. Leavitt BJ, Ross CS, Spence B, Surgenor SD, Olmstead EM, et al. (2006) Long-term survival of patients with chronic obstructive pulmonary disease undergoing coronary artery bypass surgery. Circulation 114(1): I430-1434

176. Medalion B, Katz MG, Cohen AJ, Hauptman E, Sasson L, et al. (2004) Long-term beneficial effect of coronary artery bypass grafting in patients with COPD. Chest 125(1): 56-62.

177. Samuels LE, Kaufman MS, Morris RJ, Promisloff R, Brockman SK (1998) Coronary artery bypass grafting in patients with COPD. Chest 1998 113(4): 878-882.

178. Bypass Angioplasty Revascularization Investigation (BARI) Investigators (1996) Comparison of coronary bypass surgery with angioplasty in patients with multivessel disease. N Engl J Med 335(4): 217-225

179. (1997) Influence of diabetes on 5-year mortality and morbidity in a randomized trial comparing CABG and PTCA in patients with multivessel disease: the Bypass Angioplasty Revascularization Investigation (BARI). Circulation 96(6): 1761-1769.

180. Hoffman SN, Ten JAB, Wolf MP, Pauker SG, Salem DN, et al, (2003) A meta-analysis of randomized controlled trials comparing coronary artery bypass graft with percutaneous transluminal coronary angioplasty: one- to eight-year outcomes. J Am Coll Cardiol 41(8): 1293-1304

181. Phillips HR, O'Connor CM, Rogers J (2007) Revascularization for heart failure. Am Heart J 153(4): 65-73

182. Shanmugam G, Legare JF (2008) Revascularization for ischaemic cardiomyopathy. Curr Opin Cardiol 23(2): 148-152.
183. Lee TA, Wolozin B, Weiss KB, Bednar MM (2005) Assessment of the emergence of Alzheimer's disease following coronary artery bypass graft surgery or percutaneous transluminal coronary angioplasty. J Alzheimers Dis 7(4): 319-324.

184. Raja PV, Blumenthal JA, Doraiswamy PM (2004) Cognitive deficits following coronary artery bypass grafting: prevalence, prognosis, and therapeutic strategies. CNS Spectr 9(10): 763-772.

185. Fujimoto Y, Ishiwata S, Dohi T, Masuda J, Fujimoto H, et al. (2007) Long-term prognosis after coronary revascularization in patients with end-stage renal disease on dialysis: comparison of percutaneous coronary intervention and coronary artery bypass grafting [in Japanese]. J Cardiol 50(1): 11-20.

186. Ivens K, Gradaus F, Heering P, Schoebel FC, Klein M, et al. (2001) Myocardial revascularization in patients with end-stage renal disease: comparison of percutaneous transluminal coronary angioplasty and coronary artery bypass grafting. Int Urol Nephrol 32(4): 717-723.

187. Szczech LA, Reddan DN, Owen WF, Califf R, Racz M, et al. (2001) Differential survival after coronary revascularization procedures among patients with renal insufficiency. Kidney Int 60(1): 292-299.

188. Saw J, Levin A, Gin K (2004) Coronary artery disease in chronic kidney disease patients: assessing the evidence for diagnosis, screening and revascularization. Can J Cardiol 20(8): 807-813.

189. Singh M, Lennon RJ, Holmes DR, Bell MR, Rihal CS (2002) Correlates of procedural complications and a simple integer risk score for percutaneous coronary intervention. J Am Coll Cardiol 40(3): $387-$ 393.

190. Tran HA, Barnett SD, Hunt SL, Chon A, Ad N (2009) The effects of previous coronary artery stenting on short and intermediate term outcome after surgical revascularisation in patients with diabetes mellitus. J Thorac Cardiovasc Surgery 138(2): 316-324.

191. Lazar HL (2009) Detrimental effects of coronary stenting on subsequent coronary artery bypass surgery: Is there another flag on the field? J Thorac Cardiovasc Surg 138(2): 276-277.

192. Larobina ME, Merry CJ, Negri JC, Pick AW (2007) Is informed consent in cardiac surgery and percutaneous coronary intervention achievable? ANZ J Surg 77(7): 530-534.

193. Tonino PA, De Bruyne B, Pijls NH, Siebert U, Ikeno F, et al. (2009) Fractional flow reserve versus angiography for guiding percutaneous coronary intervention. N Engl J Med 360(3): 213-224.

194. Pijls NH, De Bruyne B, Peels K, Van Der Voort PH, Bonnier HJ, et al. (1996) Measurement of fractional flow reserve to assess the functional severity of coronary-artery stenoses. N Engl J Med 334(26): 1703-1708.

\section{Your next submission with Juniper Publishers} will reach you the below assets

- Quality Editorial service

- Swift Peer Review

- Reprints availability

- E-prints Service

- Manuscript Podcast for convenient understanding

- Global attainment for your research

- Manuscript accessibility in different formats

( Pdf, E-pub, Full Text, Audio)

- Unceasing customer service

Track the below URL for one-step submission

https://juniperpublishers.com/online-submission.php 